\title{
Pearls Become Swine
}

Casey Stannard, Louisiana State University, USA

Keywords: feral pig leather, shibori felting, knitting

Purpose: The Southern United States has a huge population of feral hogs. These hogs can destroy vegetation, harm other species, and even carry diseases that can be transmitted to humans (Barrios-Garcia \& Ballari, 2012). Due to these issues feral hogs are frequently culled and yet the

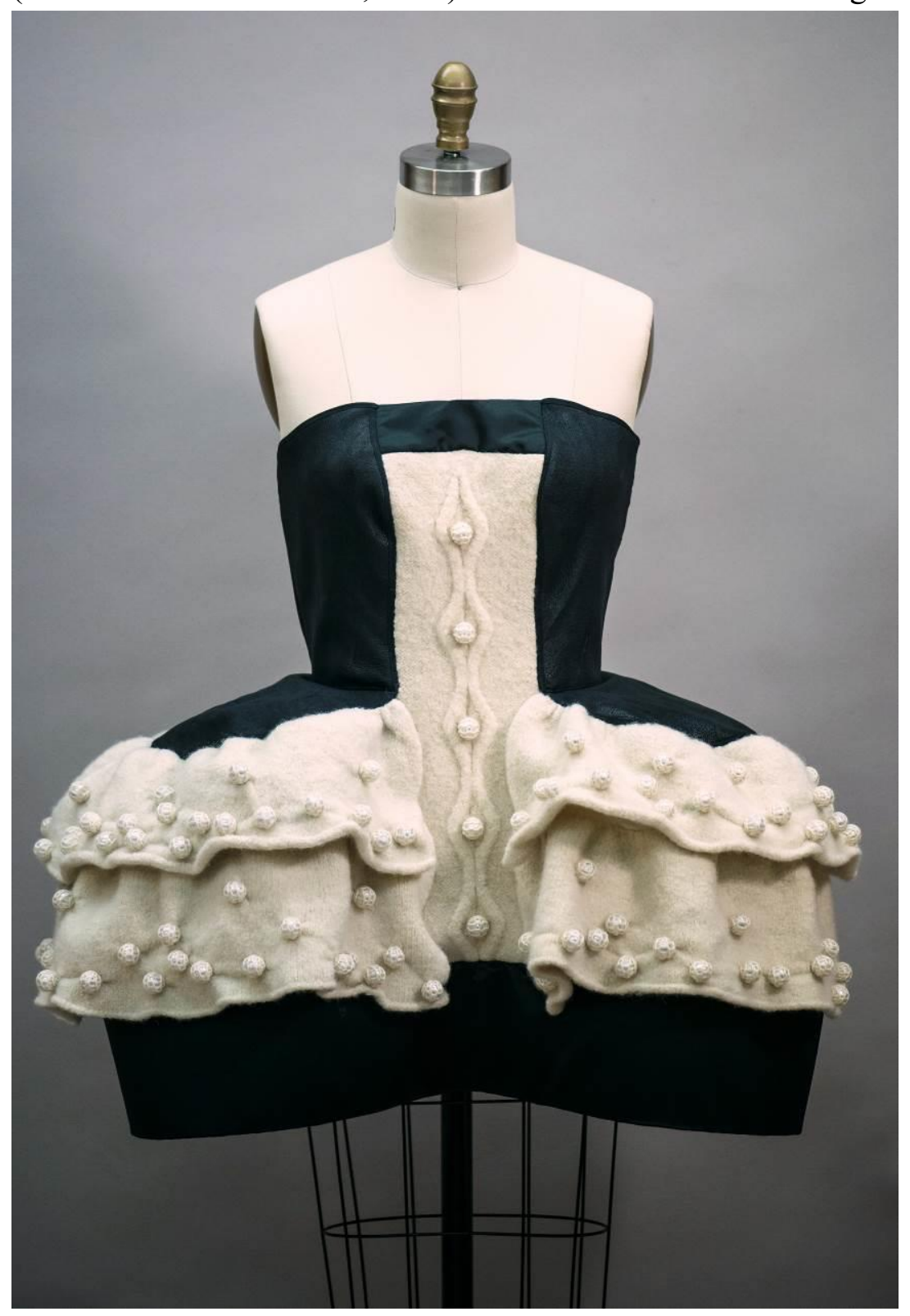
hides are not typically utilized. Therefore, the purpose of this design was to explore feral hog leather for use in apparel.

The design was a play on the old saying, "do not cast pearls before swine." The design instead uses the pearls to accent the pig leather. The pearls were encased in knit fabric using Shibori felting. However, the pearls were not removed after felting as is typically done.

Process: The design started with knitting the front panel and ruffles on a knitting machine. The cables on the front panel were hand manipulated. Next, pearl beads were individually sewn into the body of the fabric. Each piece was then felted in a washing machine.

The dress was draped around the felted front panel. Panniers were constructed with boning and stuffing. The 
felted ruffles dictated the final pannier size. Each ruffle was hand stitched onto the panniers.

The feral pig leather was hand-dyed and the edges were bound prior to being applied to the dress. Finally, a deep hem of black satin was added. A separating zipper was included along the entire center back to ease donning and doffing.

Cohesion was created by featuring pearls along with the leather to relate to the inspiration. Another goal of this piece was to create a visually striking design to showcase the potential of feral pig leather for apparel.

Contribution: Demonstrating the application of an underutilized agricultural resource for apparel products is the major contribution of this piece. The piece also incorporated a novel approach to Shibori felting.

Techniques: Shibori felting, knitting, leather sewing.

Materials: Feral pig leather, wool yarn, black polyester satin, plastic canvas

Barrios-Garcia, M. N., \& Ballari, S. A. (2012). Impact of wild boar (Sus scrofa) in its introduced and native range: a review.

Biological Invasions, 14(11), 2283-2300.

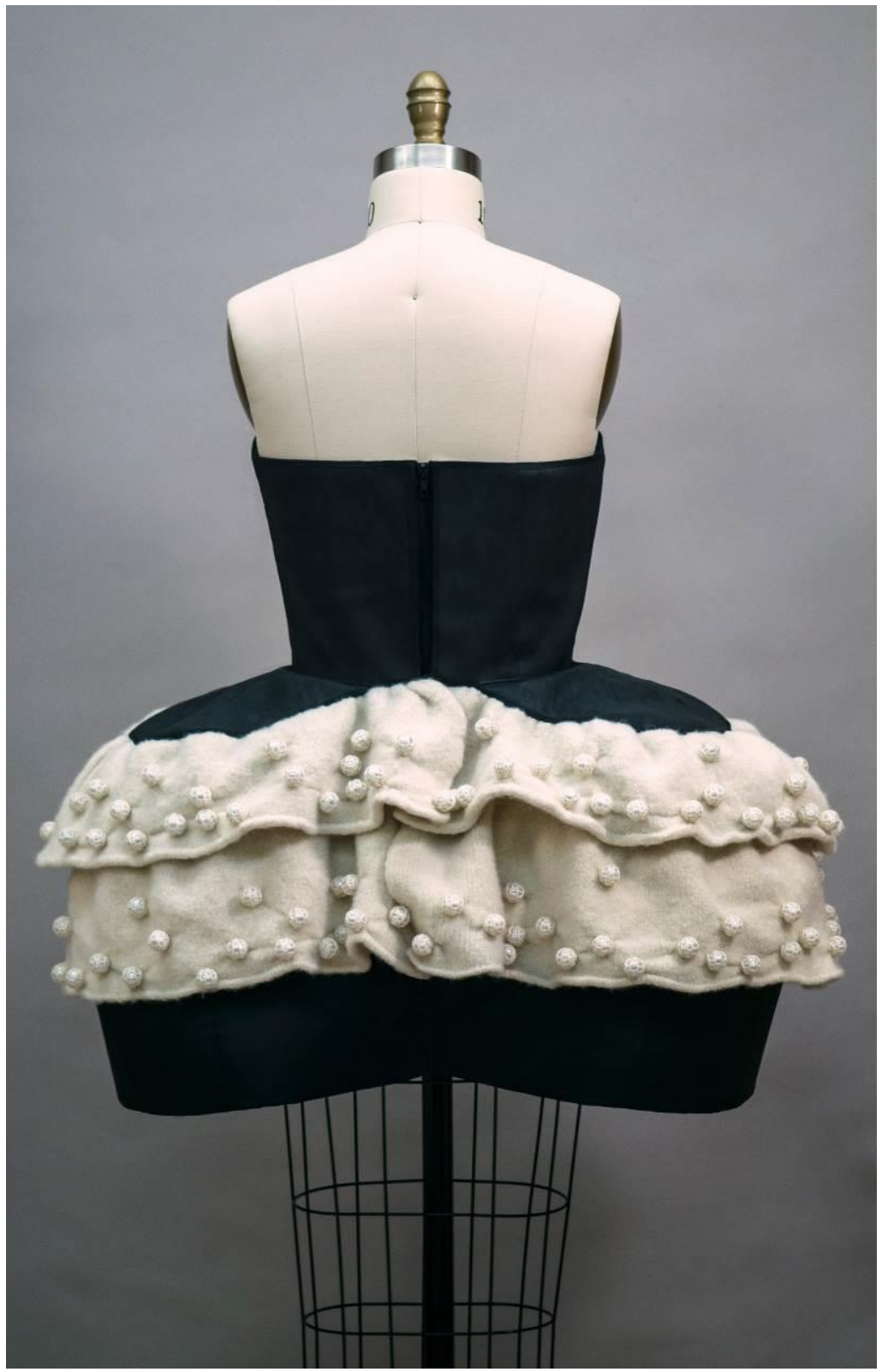

